\title{
SERUM FERRITIN;
}

COMPARISON OF BONE AGE OF THALASEMIC PATIENTS 9-15 YEARS

1. MBBS, M.Phil, Assistant Professor, Department of Anatomy, Ayub Medical College, Abbott Abad. 2. MBBS, M.Phil,

Assistant Professor Department of Anatomy, Bacha Khan Medical College, Mardan.

3. MBBS, FCPS,

Associate Professor, Department of Anatomy, Bacha Khan Medical College, Mardan.

\section{Correspondence Address:} Dr. Wajid Akbar

Department of Anatomy, Bacha Khan Medical College, Mardan drwajidakbar@yahoo.com

Article received on: 15/09/2017

Accepted for publication

15/12/2017

Received after proof reading: 28/02/2018

\section{Humaira Imtiaz', Wajid Akbar ${ }^{2}$, Usman $\mathrm{Ali}^{3}$}

ABSTRACT... Objectives: The aims is to determine whether there is any difference between the bone age of thalassemic children with chronological age and serum ferritin and its correlation with normal children of the same age. Study design: This was cross sectional analytical study. Place \& Duration: The study was conducted as age sex matched normal control, from Fatimid and Khyber Teaching Hospital Peshawar during August 2014 to January 2015. Material \& Methods: A total 156 samples were selected conveniently to make comparison of bone age between thalassemic children (age 9-15years) and control. A structure data collection check list was used to collect data X-ray findings (bone age) and Ferritin level. Data were analyzed using SPSS version 20 and MS Excel. The frequency, proportion, percentages, ratio, means and SD were calculated. Student's t- test was applied to compare the means of biochemical measures between the two groups, $P$ value $\leq 0.05$. Results: The results indicate total 156 children were included with mean age $11.9 \pm 2.2,\{97(62.2 \%)$ were being males and $59(37.8 \%)$ were being females $\}$. Out of thalassemic $(n=76)$ majority $49(62.8 \%)$ were male as compare to female $29(37.2 \%)$. The bone age was significantly different from control $(p=0001)$. Similarly the mean ferritin concentrations were also different $(P=0001)$. Conclusion: Serum ferritin level could be one of the indictors for osteoporosis and thus may play an imperative role in the management of thalassemia patients by early diagnosis and treatment.

Key words: $\quad$ Bone Age, Chronological Age, B-Thalassemia Major, Ferritin.

Article Citation: Imtiaz H, Akbar W, Ali U. Serum ferritin; comparison of bone age of thalasemic patients 9-15 years. Professional Med J 2018; 25(3):454-460. DOI:10.29309/TPMJ/18.4316

\section{INTRODUCTION}

Thalassemia is a Greek word, having a single gene disorder in which there is defective synthesis of either a or $\beta$ globin, which are hemoglobin subunits, in this type of anemia there is either deletion or mutation of alleles of globin genes of 11 and 16 respectively. ${ }^{1,2}$ It is a disease of childhood which is evident in the early few months of life, which manifest as enlargement of heart and liver osteopenia, extramedullary haemopoeisis causing formation of abnormal masses. ${ }^{3,4}$ The life expectancy of thalasessemic has been increased due to modern therapy and comprehensive care complications are delayed.5,6 Multiple blood transfusions have improved the survival of patients but there is a major side effect of transfusions i.e. iron overload. ${ }^{4}$ Iron accumulates in major organs causing cardiomyopathy, liver damage, hypothyroidism, hypoparathyroidism and osteopenia. Bone age, reveal physical maturity and may reflect "biological age", which is predominantly helpful to clinically assess the children with puberty and/or growth disorders. ${ }^{8,9}$ Besides assessment of bone age, the x-ray of wrist and hand also provide valuable information of bone shape. ${ }^{10}$

Bone age is predominantly helpful in the clinical assessment of children with puberty and/or growth disorders. ${ }^{11}$ It is also considered as diagnosis of precocious puberty (differential diagnosis with premature pubarche) or conditions of hyperandrogenism such as congenital adrenal hyperplasia $(\mathrm{CAH})$ characterized by advanced bone age. ${ }^{12,13}$ Bone age assessment is an important tool in pediatrics to diagnose growth and height abnormalities. Both computerized and manual methods for age determination are essential. The determination of bone age is based on the three basic parameters; (a) status of 
ossification of primary and secondary centers (b) growth of both centers, and (c) timing of fusion of the primary and secondary centers. ${ }^{14}$ The pattern of wrist bones ossification is a fairly predictable manner and age specific till adolescence when the elongation of bone is complete. Thus, the standards of bone age have been derived by comparing the level of maturation of hand and wrist bones with normal age levels. The bone ossification can be assessed by either traditional method (radiograph) or by ultrasound methods where hand bones are being tried but have yet not been validated..$^{15}$ To date, radiographs of the hand are the investigation of choice for bone age assessment. A standard posterior-anterior (PA) view of the hand and wrist is ideal for visualization of hand bone. ${ }^{16}$

Metabolic bone disease represents a major cause of morbidity in patients with thalassaemia. Bone disease in thalassemia in the form of low bone mass remains a frequent, debilitating and poorly understood problem, even among well transfused and chelated pre-pubertal and adult patients. The bone disease in Thalassemia is inadequately understood because of it multidimensional causes which result into low bone mineral density (BMD) in the thalassemic patients. This in turn led to defective growths affecting both weight and heights of the subjects. Multiple blood transfusions in thalassemia patients lead to iron overload in bone tissue. Iron overload can be determined by serum ferritin measurement. Several studies have evaluated association between serum ferritin level and growth, but without bone age examination. ${ }^{17}$

Aim of my study is to develop a reliable, feasible and cost effective method to document growth retardation in thalassemic children through skeletal age, for which we have performed various investigations like $\mathrm{x}$-ray wrist bones and teeth counting, as growth retardation cause pubertal failure which is evident in adolescents. Their bone age was correlated with serum ferritin level. The objective of the present study is to compare skeletal age of thalassemic children of 9-15 years with chronological age by $x$-ray wrist bones and by growth hormone and its correlation with normal children of same age.

\section{MATERIAL AND METHODS}

This was cross sectional analytical study based on comparison of bone age and chronological age between thalassemic children and normal control, having similar demographic characteristics. The study was conducted in conjunction with Fatimid Hospital Peshawar Pakistan (a major Thalassemia care centre) and Khyber teaching Hospital Peshawar (Department of pediatrics). It carries more than 100 blood transfusions on site per day and provides more than 100 units of whole blood and Packed RBCs per day. The study was conducted during the month of August 2014 to January 2015.

All subjects in the control group were selected from the Out Patients Department (OPD) of pediatrics for minor illness (other than Thalassemia) Khyber Teaching Hospital. List of thalassemic patients was obtained from the centres (admission counter). The official data shows that average 115 patient's reports each month in the Fatimid hospital, hence keeping in the three months of research projects; we assumed a total population of 350 patients. According to the literature anticipated population proportion in Pakistan was 5-7\%. ${ }^{18}$ Using the Epiinfo version 6 / WHO software; the calculated sample size was; $n=156$ by considering:

$$
\mathrm{n}=\frac{z_{1-\alpha / 2}^{2} \mathrm{P}(1-\mathrm{P}) \mathrm{N}}{\mathrm{d}^{2}(\mathrm{~N}-1)+z_{1-\alpha / 2}^{2} \mathrm{P}(1-\mathrm{P})}
$$

The population size from which sample selected were $\mathrm{N}=350$, anticipated population proportion $\mathrm{P}=0.0 .07$, absolute precision $\mathrm{d}=0.03$, relative precision $£=0.4$, level of significant $1-a=95 \%$.

The study participants comprised of thalassemic patients (children) aged 9-15 years including both males and females. The children with similar age, sex and height were selected from Out Patients Department (OPD) of pediatrics for minor illness (other than Thalassemia) Khyber Teaching Hospital. The inclusion criteria were; diagnosed cases of beta Thalassemia major patients 9-15 
years ofage, not suffering from any serious hepatic, renal, cardiac diseases, diabetes mellitus or any other serious infections, thalassemic patients with known birth record, thalassemic patients with no history of any other anemia. The exclusion criteria were; Children whose exact birth dates could not be verified because of incomplete birth records or lack of birth records, thalassemic patients with other metabolic or skeletal deformities not related to Thalassemia, patients with anemia other than Thalassemia, short stature due to other chronic systemic disease or hereditary bone dysplasia, radiographs not of sufficient quality or had poor positioning so that bone-age could not be determined.

The research team consists of a principal investigator and two research assistants. The data collection was carried out over a period of three months. The ethical approval was taken from Ethical Review Committee (ASRB) of Khyber Medical University Peshawar. A written informed consent was taken from the study participants after conveying the purpose of the survey and ensuring confidentiality. A structure data collection check list was used in current study to manage the data. The structured check list was broadly divided into three parts; demographic data, serum Feritin level, data regarding the bone age (based on X-ray finding).

Hand wrist radiographs were performed on 76 of thalassemic patients and 76 of normal control. The radiographs allowed an assessment of the degree of maturation and the fusion of the epiphysis with the diaphysis of the radius bone. The technique consisted of an occlusal film positioned under the wrist, with the palm facing down. With an exposure time of 0.8 seconds, a $40 \mathrm{~cm}$ cone was positioned perpendicular to the position of the hand and the film, and the radiographs were acquired. The films were processed on automated machine. After complete drying and identification these films were stored for evaluation.

Bone age was collected for each of the patients based on Greulich and Pyle's 1959 standards (GP2). All of the patient's bone age was assessed according to the GP2 atlas method. The findings were also reviewed by another certified radiologist to enhance the accuracy.

The patients were advised to fast for at least 12 hours before the biochemical analysis. A blood sample of $3 \mathrm{ml}$ was collected in an EDTA tube from the thalassemic patients and controls. The sample was stored at $2-8^{\circ} \mathrm{C}$ and then transferred to the laboratory for analysis. Serum feritin level was examined by ECLIA method. The results were classified into two groups: $<5,000 \mathrm{ng} / \mathrm{dL}$ and $>5,000 \mathrm{ng} / \mathrm{dL}$. Association between age and serum ferritin level with bone age deficit was also analyzed with regression logistic. Data was analyzed using statistical package for the social sciences (SPSS) 20.0 windows .The frequency, proportion, percentages, ratio, means and SD were calculated. For continuous variables like age of respondents, means, mean difference and SD were calculated. For each of categorical variables like gender, ossification centers appearance frequency, proportion, percentages were calculated. The chi square test was applied to compare the ossification centers in wrist bones of thalassemic patients with normal children. Serum ferritin level was determined and the students test was used to compare the means of biochemical values between the two groups. $P$ value $\leq 0.05$ was considered significant.

\section{RESULTS}

The result indicate total 156 children were included with mean age $11.9 \pm 2.2,\{97(62.2 \%)$ were being males and 59 (37.8\%) were being females . Detail categorization of age indicate that 35 (22.4\%) were from 15 years of age group, followed by $29(18.60 \%)$ in 10 years, $24(15.40 \%) 9$ years, 22 (14.10\%) 12 years, $16(10.30 \%) 14$ years, $14(9 \%)$ 11 years, $10(6.4 \%) 13$ years, 4 (2.5\%) 9.5 years and $2(1.3 \%)$ were from 10.5 years respectively; age category of the participants. (Figure-1)

Out of 156 participants 97 (62.2\%) were being males and 59 (37.8\%) were being females. The thalassemic patients $49(62.8 \%)$ male and 29 (37.2\%) females and approximately similar ratio 48 (61.5\%) male and 30 (38.5\%) female. (Figure-2) Out of 79 cases from Fatimid Hospital, $76(96.20 \%)$ were thalassaemic patients and 
$3(3.79 \%)$ were normal. While the comparative groups was selected from Pediatric ward, Khyber teaching hospital, among 77 cases 2 (2.59\%) were thalassaemic patients while 75 (97.40\%) were normal. (Figure-3)

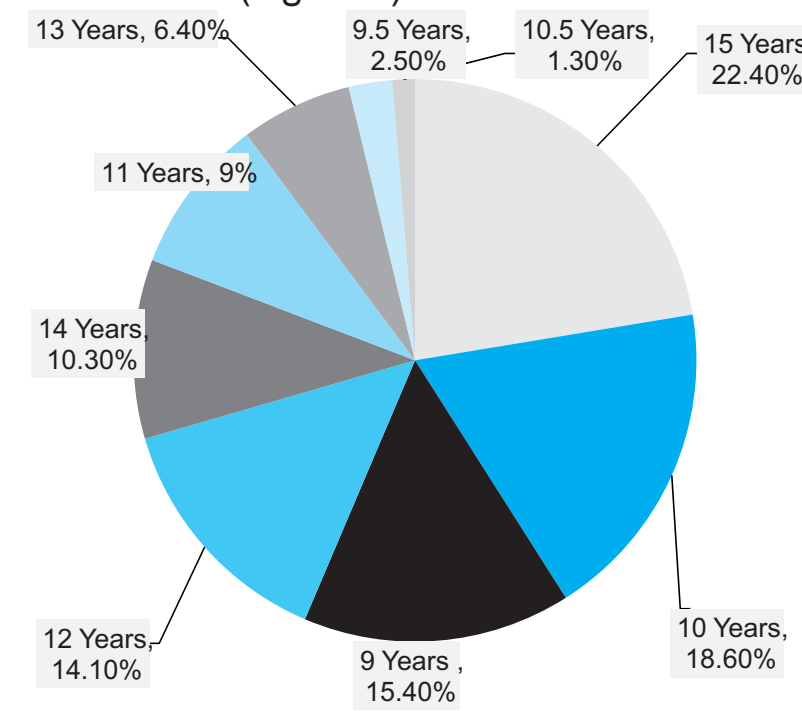

Figure-1. Age categorization of the participants

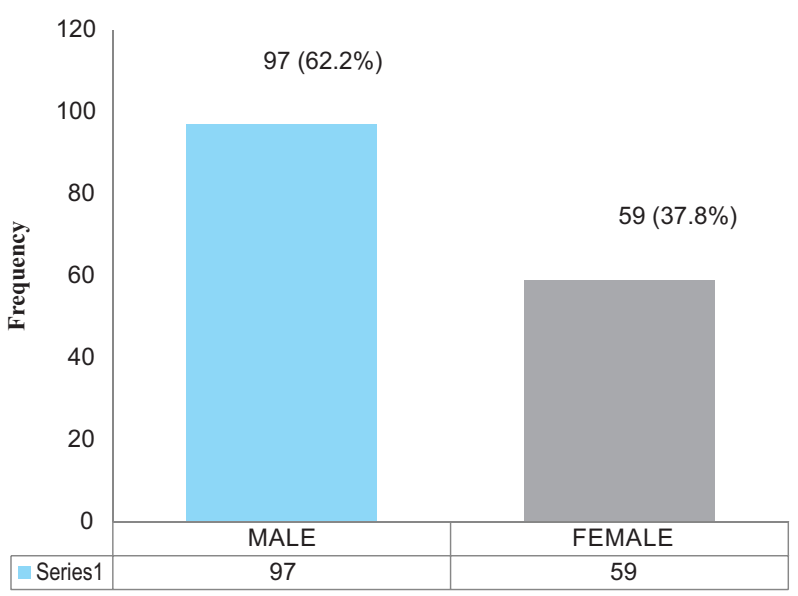

Figure-2. Over all gender distribution among study sample

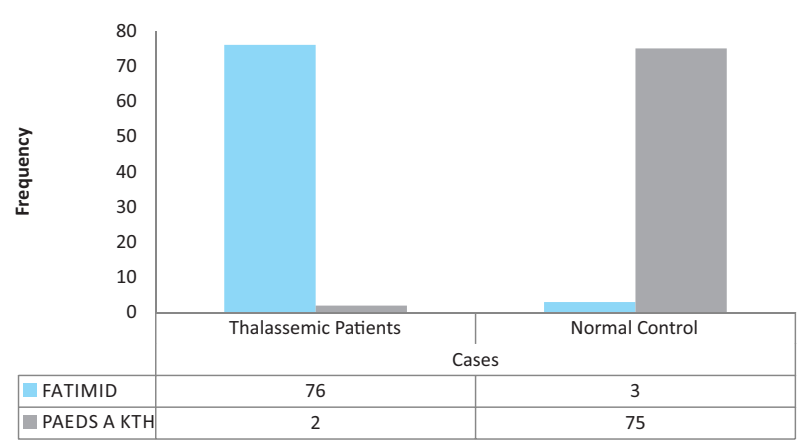

Figure-3. Area profile of study participants
Our study finding reveals that the mean chorological age among thalassemic patients was $12.01 \pm 2.2$ (ranged 09 to15 years), where $50 \%$ were more than 12 years of age. Similarly, among control group the mean chronological age was $11.86 \pm 2.18$ (range 9 to 15 years with median of 12.0 years), indicating the mean difference of 0.154 years $(p=0.67)$ which is not significant and reveals a good matching during selection of control group as shown in (Figure-4).

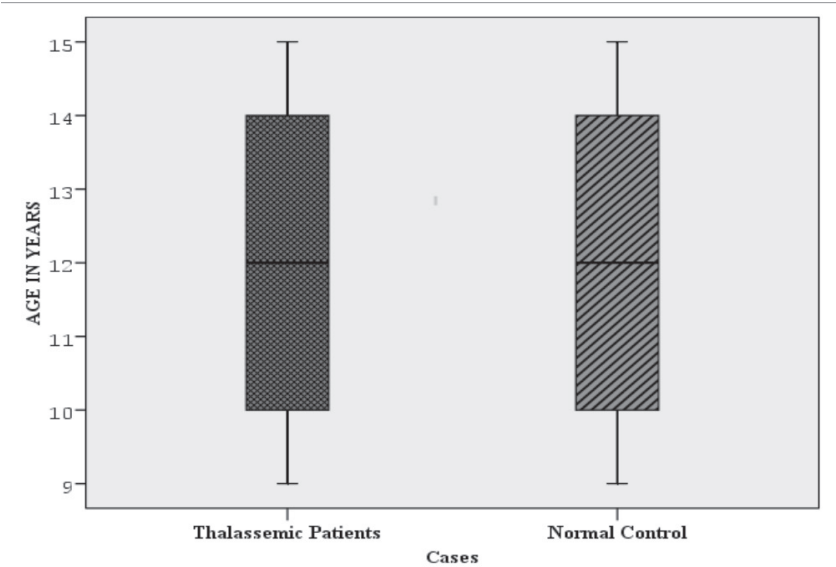

Figure-4. Comparison of chronological age between two groups

The overall mean chronological age among both the groups was similar. However, the mean bone age between the two groups was significantly different. The mean bone age was significantly lesser in thalassaemic patients as compared to control group. Figure-3, (Table-l)

Result reveals that mean bone age among thalassemic patients $(9.9 \pm 1.6$ years) were less as compared to control group (11.7 \pm 2.5$)$ with mean difference of 1.7 years which indicate that the average bone age of thalassemic patient needs more 1.7 years to acquire bone maturity. (Figure-5)

The mean serum ferritin level among thalassemic patients $(786.12 \pm 416.39 \mathrm{mcg} / \mathrm{l})$ were significantly higher $(P=0001)$ as compare to control group (58.66 $\pm 74.45 \mathrm{mcg} / \mathrm{l})$ and bone age was positively associated with serum ferritin level $(r=0.145, p=0.204)$. Table-l, II. Bone age was strongly associated with serum ferritin $(r=0$. $.467^{\star *}, p=0.0001$ ). (Table-III) 


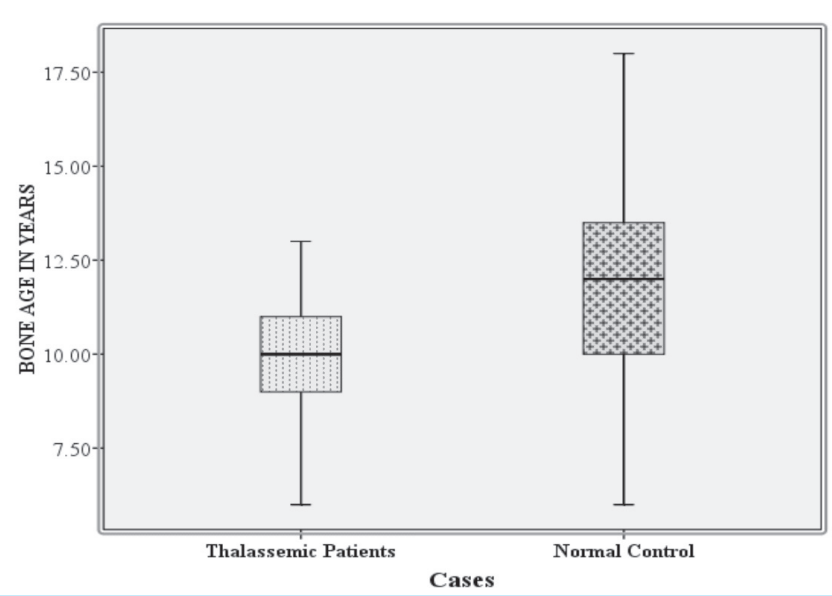

Figure-5. Comparison of bone age among thalassemic and normal children

\section{DISCUSSION}

Thalassemia is a genetic problem due to defective alpha or beta hemoglobin chain synthesis which in turn leads to an ineffective erythropoiesis requiring continues transfusion therapy in its most severe form. ${ }^{1,2,3}$ This condition then lead to hormonal complications and iron overload, which are implicated in bone deformity and loss of bone mineral density (BMD). ${ }^{6}$ The resultant outcome of overall bone related physiology could probably lead to the alteration and bone maturity among the children. ${ }^{8}$

The gender distribution of the study population indicate the frequency of the male patients was high as compared the female i.e. $49(62.8 \%)$ males and 22 (37.2\%) females. Studies have reported that male patients were more frequently affected than females (92.3\% vs. 88.0\%). Furthermore they also found that this gender difference is not only in the prevalence of osteoporosis/osteopenia in thalassemic patients, but also in the severity of the disorder, as males are more frequently and severely affected than females. ${ }^{19}$

The present study reveals that the mean bone age (9.9 \pm 1.6 years) of thalassemia patients was significantly different from control groups (11.7 \pm 2.5$),(p=0001)$. The bone age of thalassemic patient remains low as compare to the control group and it is found by majority of the studies. ${ }^{8}$ This trend in the variation of bone age and chronological age is due to the bone mass density. The bone mass density among thalassemic patients remains low as compared to the normal as predicted by other studies. According to them low bone mass density is often present in patients with thalassemia, although recognized late, as in the present series. Early diagnosis should be done during childhood, in order to improve the quality of life in adulthood. ${ }^{21}$ Studies also have reported that the mean survival age of Indian thalassemic patients have been increased due to modern therapies but it is becoming increasingly clear that as the patients approach the age of puberty, many develop growth retardation and pubertal failure. ${ }^{22}$

The thalassemia patients are at risk of disproportionate trunkal shortening, due to platyspondyly resulting from a combination of factors like hemosiderosis, desferrioxamine toxicity or deficiency of trace elements. ${ }^{23}$ In case of thalassemia, frequent blood transfusion is needed because of ineffective erythropoiesis which increases gastro-intestinal iron absorption resulting in iron overload. This overload makes the immune system worse, prefacing the patients at high risk of infection and other illness. Such condition can be verified by determining the serum ferritin level. ${ }^{24,25}$ In the current study ferritin level, was found high among thalassemic patients $(786.12 \pm 416.39 \mathrm{mcg} / \mathrm{l})$ as compare to control group (58.66 $\pm 74.45 \mathrm{mcg} / \mathrm{l})$, showing a significant difference $(P=0001)$. Similar findings were reported by other studies, which indicate that the mean serum ferritin concentration in the thalassemic patients was $101.84+/-8.5$ microg/L, which was higher as compared to control group (67.98+/-5.4 microg/L, $p=0.001)$. Moreover, they compared that this was significantly higher among male subjects. ${ }^{26}$ This indicates that the thalassemia may play a role in improving iron status in females with disease. However in males, thalassemia can lead to iron overload. Therefore, investigation of serum ferritin level in subjects with $\beta$ thalasaemia major is a standard way, especially in males, to avoid harmful effects of iron overload in early stages of the disorder. ${ }^{27}$ The increased serum ferritin level could be contributed to multiple life-long transfusions and enhanced iron absorption results in secondary 
hemosiderosis. ${ }^{28}$ Studies have revealed that thalassemic children had significantly higher serum ferritin levels compared with the controls. No significant difference was found in serum ferritin between thalassaemia major and thalassaemia intermedia. ${ }^{29}$ Furthermore other studies have demonstrated that besides serum ferritin level, lipid profile is also deranged in the thalassemic patients. ${ }^{30}$

In the present study there is a positive correlation between bone age and serum ferritin level $(r=$ $0.145, p=0.204$ ) and with the growth hormone $\left(r=0.244^{*}, p=0.031\right)$ respectively. The same trend was also reported by other studies which have observed that in all patients with thalassemia, bone age, growth hormone stimulation, insulinlike growth factor (IGF)-1 level, IGF-BP3 level have decreased. Height velocity or delayed bone age, desferrioxamine toxicity, other hormonal and nutritional imbalances) were also observed. ${ }^{31}$ This is because of decrease in bone mass which can happen due to augmented bone resorption or decreased bone formation both of which can lead to osteopenia/osteoporosis in thalassemia. ${ }^{32}$

\section{CONCLUSION \& RECOMMENDATIONS}

Hand wrist radiographs, growth hormones levels, ferritin level and dental eruption are important parameters in the investigation of thalassemic patients and serum ferritin level could be one of the indictors for osteoporosis and thus may play an imperative role in the management of thalassemia patients by early diagnosis and treatment. However, further investigations are required to establish the correlation between growth hormones and serum ferritin levels in thalasaemic patient.

Copyright(C) 15 Dec, 2017.

\section{REFERENCES}

1. Hashemi AM, Ghilian RM, Golestan MM. The study of growth in thalassemic patients and its correlation with serum ferritin level. Iranian Journal of Pediatric Hematology Oncology. 2011; 1(4):147-50.

2. Nasr MR, EbrahimNA, Ramadan MS, Salahedin O. Growth pattern in children with beta thalassemia major and its relation with serum ferritin, IGF1 and IGFBP3. Journal of clinical and experimental investigations. 2012; 3(2):157-63.
3. Borgna-Pignatti C, Rugolotto S, De Stefano P, Zhao H, Cappellini MD, Del Vecchio GC, et al. Survival and complications in patients with thalassemia major treated with transfusion and deferoxamine. Haematologica. 2004 Oct; 89(10):1187-93.

4. Mazzone L, Battaglia L, Andreozzi F, Romeo MA, Mazzone D. Emotional impact in beta-thalassaemia major children following cognitive-behavioural family therapy and quality of life of care giving mothers. Clin Pract Epidemiol Ment Health. 2009; 5:5.

5. Adil A, Sobani ZA, Jabbar A, Adil SN, Awan S. Endocrine complications in patients of beta thalassemia major in a tertiary care hospital in Pakistan. J Pak Med Assoc. 2012 Mar; 62(3):307-10.

6. Mokhtar GM, Tantawy AA, Adly AA, Ismail EA. Clinicopathological and radiological study of Egyptian beta-thalassemia intermedia and betathalassemia major patients: relation to complications and response to therapy. Hemoglobin. 2011; 35(4):382-405.

7. Skordis N, Kyriakou A. The multifactorial origin of growth failure in thalassaemia. Pediatr Endocrinol Rev. 2011 Mar; 8 Suppl 2:271-7.

8. Cantekin K, Celikoglu M, Miloglu O, Dane A, Erdem A. Bone age assessment: the applicability of the Greulich-Pyle method in eastern Turkish children. $J$ Forensic Sci. 2012 May; 57(3):679-82.

9. Soudack M, Ben-Shlush A, Jacobson J, Raviv-Zilka L, Eshed I, Hamiel O. Bone age in the 21st century: is Greulich and Pyle's atlas accurate for Israeli children? Pediatr Radiol. 2012 Mar; 42(3):343-8.

10. Heppe DH, Taal HR, Ernst GD, Van Den Akker EL, Lequin MM, Hokken-Koelega AC, et al. Bone age assessment by dual-energy $\mathrm{X}$-ray absorptiometry in children: an alternative for X-ray? Br J Radiol. 2012 Feb; 85(1010):114-20.

11. McCalden RW, McGeough JA, Court-Brown CM. Agerelated changes in the compressive strength of cancellous bone. The relative importance of changes in density and trabecular architecture. J Bone Joint Surg Am. 1997 Mar; 79(3):421-7.

12. Harrington J, Palmert MR. Clinical review: Distinguishing constitutional delay of growth and puberty from isolated hypogonadotropic hypogonadism: critical appraisal of available diagnostic tests. J Clin Endocrinol Metab. 2012 Sep; 97(9):3056-67.

13. Soliman AT, De Sanctis V. An approach to constitutional delay of growth and puberty. Indian J Endocrinol Metab. 2012 Sep; 16(5):698-705. 
14. Mansourvar M, Ismail MA, Herawan T, Raj RG, Kareem SA, Nasaruddin FH. Automated bone age assessment: motivation, taxonomies, and challenges. Comput Math Methods Med. 2014; 2013:391626.

15. Manzoor Mughal A, Hassan N, Ahmed A. Bone age assessment methods: a critical review. Pak J Med Sci. 2014 Jan; 30(1):211-5.

16. Bhat AK, Kumar B, Acharya A. Radiographic imaging of the wrist. Indian J Plast Surg. 2011 May;44(2):18696.

17. Kim BJ, Lee SH. Menopause may be the common link that resulted in the association between a higher serum ferritin level and lower bone mineral density in women $>/=\mathbf{4 5}$ years of age: response to Lee and Kim. Osteoporos Int. 2013 Feb; 25(2):789-90.

18. Ansari SH, Shamsi TS, Ashraf M, Farzana T, Bohray $M$, Perveen K, et al. Molecular epidemiology of betathalassemia in Pakistan: Far reaching implications. Indian J Hum Genet. 2012 May; 18(2):193-7.

19. Kyriakou A, Savva SC, Savvides I, Pangalou E, loannou YS, Christou S, et al. Gender differences in the prevalence and severity of bone disease in thalassaemia. Pediatr Endocrinol Rev. 2008 Oct; 6 Suppl 1:116-22.

20. Negi KS. Reliability of MP3 (middle phalanx of 3rd finger) Stages in Assessment of Skeletal Maturation -A Correlative Study. The Orthodont Cyber J Oct 2009:1-12.

21. Tsushima K, Sone S, Yoshikawa S, Yokoyama T, Suzuki $\mathrm{T}$, Kubo $\mathrm{K}$. The radiological patterns of interstitial change at an early phase: over a 4-year follow-up. Respir Med. 2010 Nov; 104(11):1712-21.

22. Ozer T, Kama JD, Ozer SY. A practical method for determining pubertal growth spurt. Am J Orthod Dentofacial Orthop. 2006 Aug; 130(2):131 e1-6.

23. Hattab FN. Patterns of physical growth and dental development in Jordanian children and adolescents with thalassemia major. J Oral Sci. 2013 Mar; 55(1):717.

24. Kurtoglu AU, Kurtoglu E, Temizkan AK. Effect of iron overload on endocrinopathies in patients with betathalassaemia major and intermedia. Endokrynol Pol. 2012; 63(4):260-3.

25. Mishra AK, Tiwari A. Iron overload in Beta thalassaemia major and intermedia patients. Maedica (Buchar). 2014 Sep; 8(4):328-32.

26. Hoorfar H, Sadrarhami S, Keshteli AH, Ardestani SK, Ataei M, Moafi A. Evaluation of iron status by serum ferritin level in Iranian carriers of beta thalassemia minor. Int J Vitam Nutr Res. 2008 Jul-Sep; 78(4-5):2047.

27. Shalitin S, Carmi D, Weintrob N, Phillip M, Miskin H, Kornreich $L$, et al. Serum ferritin level as a predictor of impaired growth and puberty in thalassemia major patients. Eur J Haematol. 2005 Feb; 74(2):93-100.

28. Louis CK. Growth of Children with -Thalassemia Major. Indian Journal of Pediatrics. 2005; 72(1):159-64.

29. Ali D, Mehran K, Moghaddam AG. Comparative evaluation of renal findings in Beta-thalassemia major and intermedia. Saudi J Kidney Dis Transpl. 2008 Mar; 19(2):206-9.

30. Seham M, Ragab MA, Safan, Asmaa S, Sherif. Lipid profiles in $\boldsymbol{\beta}$ thalassemic children. MMJ. 2014; 27(1):66-72.

31. Taher A, Vichinsky E, Musallam K, Cappellini MD, Viprakasit V. Guidelines for the Management of Non Transfusion Dependent Thalassaemia. 2014.

32. Voskaridou E, Kyrtsonis MC, Terpos E, Skordili M, Theodoropoulos I, Bergele A, et al. Bone resorption is increased in young adults with thalassaemia major. Br J Haematol. 2001 Jan; 112(1):36-41.

\begin{tabular}{|c|c|c|c|}
\hline \multicolumn{4}{|c|}{ AUTHORSHIP AND CONTRIBUTION DECLARATION } \\
\hline Sr. \# & Author-s Full Name & Contribution to the paper & Author $=\mathbf{s}$ Signature \\
\hline 1 & Humaira Imtiaz & Concept and design of study. & \\
\hline 2 & Wajid Akbar & Drafting and data analysis. & 21 \\
\hline 3 & Usman Ali & $\begin{array}{l}\text { Revising critically \& final } \\
\text { approval of version. }\end{array}$ & Wy \\
\hline
\end{tabular}

